\title{
CAD Model and Simulation of T-Shaped Microstrip Antenna for LTE $1800 \mathrm{MHz}$ Applications
}

\author{
S. Malisuwan, J. Sivaraks, P. Promkladpanao, and Y. Thamachareon
}

\begin{abstract}
In this paper, the simulation of proposed T-shaped microstrip antenna is presented. The proposed procedure in this research includes frequency-dependent characteristic impedance in $\mathrm{GHz}$ frequency range in the standard microstip patch antenna design methods. The proposed antenna in this paper is designed for broadband 1800MHz LTE applications in the E-UTRAN band of 1, 2, 3, 4, 9, 10 and 11. The proposed procedure and designed formulas in this research are used to construct in-house MATLAB program software which is compatible with Computer Aided Design (CAD) with fast and user-friendly implementations.
\end{abstract}

Index Terms-Microstrip antenna, T-shaped, frequency-dependent, LTE, $1800 \mathrm{MHz}$, CAD.

\section{INTRODUCTION}

In the modern day, mobile phones sizes have decreased in size and are light-weight. Due to this trend, components within the mobile phones are required to be small, light-weight and have low profile. Therefore, antennas used in mobile phones for personal communications are required to be small as well as are crucial as it can either improve or limit system preference due to the bandwidth and efficiency it provides. To carefully design a handset with superior performance, engineers must focus on the design of the antenna system of the mobile phone. The microstrip patch antenna is slim, light weight, easy for manufacturing and is suitable for small and light weight handsets.

"The microstrip patch antenna is a narrowband antenna fabricated by etching the antenna element pattern in metal trace bonded to an insulating dielectric substrate with a continuous metal layer bonded to the opposite side of the substrate which forms a ground plane" [1].. Narrow bandwidth is a serious limitation of the microstrip patch antennas. There are many successful attempts to improve the bandwidth, gain and efficiency of the microstrip antenna. These methods include variation in antenna dimensions, dielectric constant, substrate thickness and using parasitic patches [2]-[6].

The objective of this research is to design microstrip patch antenna suitable for using within LTE mobile terminals. In this paper, we present the design of T-shape patch microstrip

Manuscript received January 7, 2014; revised May 20, 2014. Financial support for this research paper is provided by National Broadcasting and Telecommunications Commission, Bangkok, Thailand.

S. Malisuwan, J. Sivaraks, and P. Promkladpanao are with National Broadcasting and Telecommunications Commission Bangkok, Thailand (e-mail: settapong.m@nbtc.go.th, jesada.s@nbtc.go.th, peerawat.p@nbtc.go.th).

Y. Thamachareon is with Royal Thai Armed Forces, Bangkok, Thailand (e-mail: yodsapon.t@nbtc.go.th). antenna by cutting four notches in rectangular patch. By cutting the slots from a patch; gain, return loss and bandwidth of microstrip antenna can be improved [6]. The methods presented in this research are "fully compatible with the needs and trends of modern computer-aided design (CAD) [7].

Large numbers of radio spectrum bands have been reserved for FDD (Frequency Division Duplex) LTE use. Table I shows the 14 E-UTRAN band used by the LTE standard for each downlink and uplink for both UE (User Equipment) and eNB (evolved NodeB) with the minimum and maximum frequencies for downlink and uplink for every band [8]. Also it shows more than 18000 channels divided to these bands.

The proposed antenna in this paper will be utilized in broadband $1800 \mathrm{MHz}$ LTE applications. The $1800 \mathrm{MHz}$ frequency band is considered the prime option for LTE international roaming as $1800 \mathrm{MHz}$ band is widely available throughout Europe, APAC, MEA and some regions of South America-thus having the potential to be a core and global band for LTE deployments.

\begin{tabular}{|c|c|c|c|c|}
\hline \multirow{2}{*}{$\begin{array}{c}\text { E-UTRAN } \\
\text { Band }\end{array}$} & \multicolumn{2}{|c|}{$\begin{array}{c}\text { Downlink (DL) } \\
\text { (UE Receive, eNB Transmit) }\end{array}$} & \multicolumn{2}{|c|}{$\begin{array}{c}\text { Uplink (DL) } \\
\text { (UE Receive, eNB Transmit) }\end{array}$} \\
\hline & $\begin{array}{c}\text { fDL_Low } \\
\text { (NUL) } \\
(\mathrm{MHz})\end{array}$ & $\begin{array}{l}\text { fDL_High } \\
(\mathrm{MHz})\end{array}$ & $\begin{array}{c}\text { FUL_Low } \\
(\mathrm{MHz})\end{array}$ & $\begin{array}{c}\text { FUL_High } \\
(\mathrm{MHz})\end{array}$ \\
\hline 1. & 2110 & 2170 & 1920 & 1980 \\
\hline 2. & 1930 & 1990 & 1850 & 1910 \\
\hline 3. & 1805 & 1880 & 1710 & 1785 \\
\hline 4. & 2110 & 2155 & 1710 & 1755 \\
\hline 5. & 869 & 894 & 824 & 849 \\
\hline 6. & 875 & 885 & 830 & 840 \\
\hline 7. & 2620 & 2690 & 2500 & 2570 \\
\hline 8. & 925 & 960 & 880 & 915 \\
\hline 9. & 1844.9 & 1879.9 & 1749.9 & 1784.9 \\
\hline 10. & 2110 & 2170 & 1710 & 1770 \\
\hline 11. & 1475.9 & 1500.9 & 1427.9 & 1452.9 \\
\hline 12. & 728 & 746 & 698 & 716 \\
\hline 13. & 746 & 756 & 777 & 787 \\
\hline 14. & 758 & 768 & 788 & 798 \\
\hline
\end{tabular}

\section{ANTENNA DESIGN}

To achieve the design objective in this research, first a rectangular microstrip patch antenna is constructed based on the standard designing procedure. For an efficient radiation a practical width of the rectangular patch element becomes [3] 


$$
w=\frac{1}{2 f_{r} \sqrt{\mu_{0} \varepsilon_{0}}} \sqrt{\frac{2}{\varepsilon_{r}+1}}
$$

And the length of the antenna becomes [8]-[10]

$$
L=\frac{1}{2 f_{r} \sqrt{\varepsilon_{e f f}} \sqrt{\varepsilon_{0} \mu_{0}}}-2 \Delta
$$

where

$$
\Delta L=0.41 h \frac{\varepsilon_{e f f}+0.3}{\varepsilon_{e f f}-0.258} \frac{\left(\frac{w}{h}+0.264\right)}{\left(\frac{w}{h}+0.8\right)}
$$

And [11]

$$
\varepsilon_{\text {eff }}=\frac{\varepsilon_{r}+1}{2}+\frac{\varepsilon_{r}-1}{2}\left(1+10 \frac{h}{w}\right)^{-B}
$$

where $B$ is given by:

$$
\begin{gathered}
B=0.564\left\{1+\frac{1}{49} \ln \left(\frac{(w / h)^{4}+(w / 52 h)^{2}}{(w / h)^{4}+.432}\right)+\frac{1}{18.7} \ln [1+\right. \\
\left.\left.\left(\frac{w}{18.1 h}\right)^{3}\right]\right\}\left(\frac{\varepsilon_{r}-0.9}{\varepsilon_{r}+3}\right)^{0.053}
\end{gathered}
$$

where, $\lambda$ is the wave length, $f_{r}$ (in $\mathrm{Hz}$ ) is the resonant frequency, $L$ and $W$ are the length and width of the patch element, in $\mathrm{cm}$, respectively and $\varepsilon_{r}$ is the relative dielectric constant.

Prior to analyzing the frequency-dependent variables, the capacitance parameter in microstrip-line system should be analyzed.

A microstrip antenna consist of a dielectric substrate which is in between the radiating patch which is on top and the ground plane which is on the other side as illustrated in Fig. 1 material) and the shape varies. The radiating patch and the feed lines are usually photo etched on the dielectric substrate.

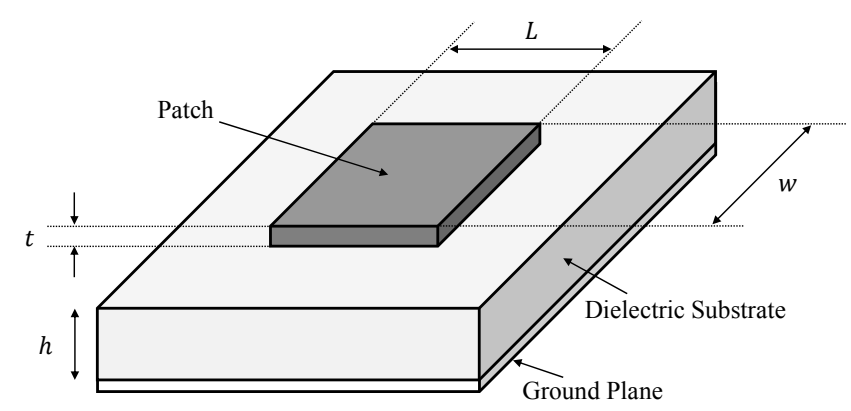

Fig. 1. Structure of a microstrip patch antenna.



Fig. 2. Dimensions of designed antenna.
The capacitance per unit length of the classical parallel-plate capacitor is [9]:

$$
C=\varepsilon \frac{w}{h}
$$

A simple frequency-dependent capacitance of the parallel-plate capacitor can be expressed in any frequency-dependent attributes of $\varepsilon$ which is

$$
C(\omega)=\varepsilon_{0} \varepsilon^{*}(\omega) \frac{w}{h}
$$

where $\varepsilon^{*}(\omega)$ is a complex permittivity is expressed as $\varepsilon^{\prime}(\omega)-j \varepsilon^{\prime \prime}(\omega)$. Therefore,

$$
C(\omega)=\varepsilon_{0} \varepsilon^{\prime}(\omega) \frac{w}{h}-j \varepsilon_{0} \varepsilon^{\prime \prime}(\omega) \frac{w}{h}
$$

Referring to the equivalent Cole-Cole diagram deduced for a parallel-plate microstrip line in is substitute into Eqn.(8). Hence,

$$
\begin{gathered}
C(\omega)=C\left(\frac{1}{1+Q(\omega)}\left[Q(\omega)+\frac{\varepsilon_{e f f}}{\varepsilon_{r}}\right]\right)-j \frac{C}{\varepsilon_{r}}\left[\varepsilon_{u}^{\prime \prime}(\omega)+\varepsilon_{c}^{\prime \prime}(\omega)+\right. \\
\left.\varepsilon_{d}^{\prime \prime}(\omega)\right]
\end{gathered}
$$

where $C=\varepsilon_{0} \varepsilon_{r}(w / h)$.

For simplicity, the coefficients of Eqn.(9) are defined as follows:

$$
\begin{gathered}
A(\omega)=\frac{1}{1+Q(\omega)}\left[Q(\omega)+\frac{\varepsilon_{\text {eff }}}{\varepsilon_{r}}\right] \\
B(\omega)=\frac{1}{\varepsilon_{r}}\left[\varepsilon_{u}^{\prime \prime}(\omega)+\varepsilon_{c}^{\prime \prime}(\omega)+\varepsilon_{d}^{\prime \prime}(\omega)\right]
\end{gathered}
$$

In general, the characteristic impedance of a transmission line is given by

$$
Z_{0}=\sqrt{\frac{R+j \omega L}{G+j \omega C}}
$$

where $R, L, G, C$ are per unit length quantities defined as follows:

$R=$ resistance per unit length in $\Omega / \mathrm{m}$.

$L=$ inductance per unit length in $H / \mathrm{m}$.

$G=$ conductance per unit length in $S / \mathrm{m}$.

$C=$ capacitance per unit length in $F / \mathrm{m}$.

If $G$ and $C$ are neglected, the characteristic impedance can be written as:

$$
Z_{0}=\sqrt{\frac{L}{C}}
$$

Frequency-dependent characteristic impedance is derived $\left(Z_{0}{ }^{\prime}(\omega)\right)$, the frequency-dependent capacitance $(C(\omega))$ of Eqn.(9) is replaced into the capacitance $(C)$ in Eqn.(13). Therefore, frequency-dependent characteristic impedance is

$$
Z_{0}^{\prime}(\omega)=\sqrt{\frac{L}{C[A(\omega)-j B(\omega)]}}=\frac{Z_{0}}{\sqrt{A(\omega)-j B(\omega)}}
$$

Now, the frequency-dependent (lossy) impedance can be derived through input of $Z_{0}^{\prime}(\omega)$ in Eqn.(14) into the normalized terminal impedance expression as done in traditional Smith-chart model [10]. Therefore the normalized terminal impedance $Z_{L}^{\prime}$ is

$$
Z_{L}^{\prime}=\frac{Z_{L}}{Z_{0}^{\prime}(\omega)}=b r+j b x \quad \text { (Dimensionless) }
$$

As $r$ and $x$ are the normalized resistance and normalized 
reactance, and $b=\sqrt{A(\omega)-j b(\omega)}$.

The voltage reflection coefficient of present Smith chart is

$$
\Gamma^{\prime}=\Gamma_{r}^{\prime}+j \Gamma_{i}^{\prime}=\frac{z_{L}^{\prime}-1}{z_{L}^{\prime}+1}
$$

Or

$$
Z_{L}^{\prime}=\frac{Z_{L}}{Z_{0}^{\prime}(\omega)}=b r+j b x=\frac{\left(1+\Gamma_{r}^{\prime}\right)+j \Gamma_{i}^{\prime}}{\left(1-\Gamma_{r}^{\prime}\right)-j \Gamma_{i}^{\prime}}
$$

The T-shaped microstrip antenna is fed by a coaxial probe. The advantage of using probe feeding is very easy to fabricate and relatively simple to model. Fig. 2 shows the designed dimensions of the proposed T-shaped microstrip patch antenna [6].

The procedure and formulas described above are used to construct in-house MATLAB program software. The calculated parameters are transferred to the software for simulation.

\section{RESULT AND DISCUSSION}

From Fig. 2, the designed specification for proposed T-shaped microstrip antenna is $53 \times 53 \mathrm{~mm}$, patch size $42.5 \times 42.5 \mathrm{~mm}$, dielectric constant $\left(\varepsilon_{r}\right)$ of 4.2 and substrate thickness $(h) 1.6 \mathrm{~mm}$ as shown in Table II.

The final stage of the design process is to find the sub-optimum position where the required bandwidth is obtained. Finally, the feed point is at $(28.45,32.55)$. The return loss of the proposed antenna is shown in Fig. 3.

\begin{tabular}{|c|c|}
\hline Parameter & Value \\
\hline $\mathrm{l}_{3} \times \mathrm{w}_{4}$ & $53 \times 53 \mathrm{~mm}^{2}$ \\
\hline patch size & $42.5 \times 42.5 \mathrm{~mm}^{2}$ \\
\hline$\varepsilon_{\mathrm{r}}$ & 4.2 \\
\hline substrate thickness & $1.6 \mathrm{~mm}$ \\
\hline $\mathrm{l}_{1}$ & $10.5 \mathrm{~mm}$ \\
\hline $\mathrm{l}_{2}$ & $16 \mathrm{~mm}$ \\
\hline $\mathrm{w}_{1}$ & $5.5 \mathrm{~mm}$ \\
\hline $\mathrm{w}_{2}$ & $5.5 \mathrm{~mm}$ \\
\hline$w_{3}$ & $31.5 \mathrm{~mm}$ \\
\hline
\end{tabular}

TABLE II: DIMENSIONS OF THE PROPOSED ANTENNA

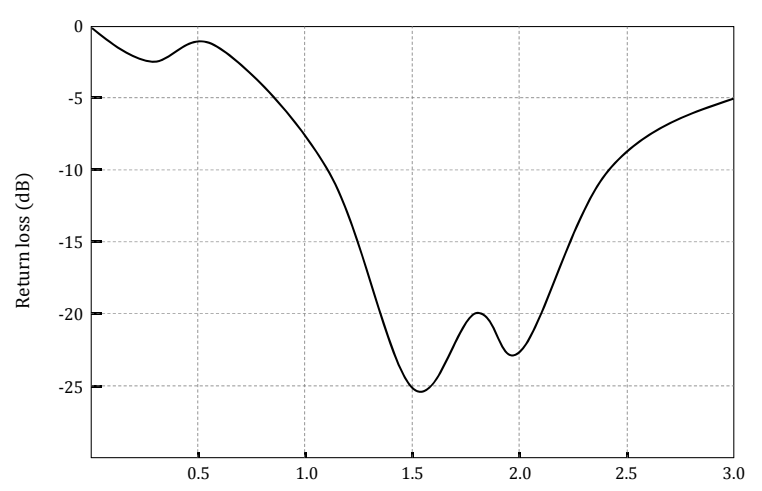

Fig. 3. Return loss of the proposed antenna.

The return loss is a way of expressing mismatch. It is a logarithmic ratio of reflected power to the power fed to the antenna. A bandwidth can be calculated from the return loss at $-10 \mathrm{~dB}$. From Fig. 3 , the bandwidth of the proposed antenna is $1.3 \mathrm{GHz}$. The results indicate that the proposed T-shaped microstrip antenna can operate at the range of $1800 \mathrm{MHz}$ LTE communication systems.

As shown in Table I, it can be observed that the proposed antenna in this paper operates in the E-UTRAN band of 1,2 , $3,4,9,10$ and 11 thereby making it suitable for LTE applications.

\section{CONCLUSION}

The results of this paper indicates that T-Shaped Microstrip Antenna is suitable for LTE deployment operating on $1800 \mathrm{MHz} .1800 \mathrm{MHz}$ is a widely used throughout the world to be a core and global band for LTE deployments. In this research it can be observed that the proposed antenna in this paper operates in the E-UTRAN band of 1, 2, 3, 4, 9, 10 and 11 thereby making it suitable for LTE applications. The proposed procedure and designed formulas in this research are used to construct in-house MATLAB program software hence it is compatible with Computer Aided Design (CAD) and is fast and user-friendly for implementation.

\section{REFERENCES}

[1] R. Kanphade, D. Wakade, and N. Markad, "Microstrip Rectangular Patch Antenna: Computer Aided Design Methology."

[2] M. Verma, S. Verma, and D. Dhubkarya, "Analysis and designing of E-shape microstrip patch antenna for the wireless communication systems," in Proc. 2009. ELECTRO'09. International Conference on Emerging Trends in Electronic and Photonic Devices \& Systems, pp. 324-327, 2009.

[3] R. Garg, Microstrip Antenna Design Handbook, Artech House, 2001.

[4] D. M. Pozar, "Microstrip antenna aperture-coupled to a microstripline," Electronics letters, vol. 21, pp. 49-50, 1985.

[5] C. A. Balanis, Antenna Theory: Analysis and Design, John Wiley \& Sons, 2012.

[6] G. Kumar and K. Ray, Broadband Microstrip Antennas, Artech House, 2003.

[7] S. Malisuwan and M. Charoenwattanaporn, "Modified Smith-chart representation as applied to microstrip antenna design for wireless LAN applications," in Proc. EMC '03. 2003 IEEE International Symposium on Electromagnetic Compatibility, 2003, pp. 150-153 vol. 1.

[8] S. M. Besen, "The European telecommunications standards institute: A preliminary analysis," Telecommunications Policy, vol. 14, pp. 521-530, 1990.

[9] S. Malisuwan, M. Charoenwattanapom, S. Huvanandana, and K. Rosesukon, "Design of microstrip antenna for bluetooth and WLAN applications by applying modified Smith-chart representation," in Proc. Asia-Pacific Conference on Applied Electromagnetics, 2003., 2003, pp. 38-41.

[10] S. Malisuwan, M. Charoenwattanaporn, U. Goenchanart, and V. Ungvichian, "Microstrip antenna for wireless LAN applications by applying modified smith-chart representation," International Journal of The Computer, The Internet and Management, vol. 11, pp. 34 - 44, 2003.

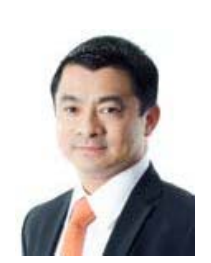

Settapong Malisuwan was born in Bangkok, Thailand in 1966. He received his $\mathrm{PhD}$ in electrical engineering (telecommunications), specializing in EMI/EMC from Florida Atlantic University (State University System of Florida), Boca Raton in 2000. He received an MSc in electrical engineering in mobile communications system, from George Washington University in 1996, an MSc in electrical engineering from Georgia Institute of Technology in 1992 and a BSc in electrical engineering from the Chulachomklao Royal Military Academy, Nakhon-Nayok, Thailand in 1990. He served in the Royal Thai Armed Forces for more than 25 years. His research interests are in efficient spectrum management and telecommunications policy and management. Col. Dr. Settapong Malisuwan is currently the elected vice chairman and board member in the national broadcasting and telecommunications commission, Thailand. 


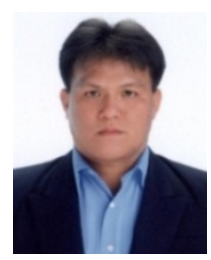

Jesada Sivaraks was born in Bangkok, in 1970, in Thailand. He received his MSEE degree from Oklahoma State University in 1996 and BEng from King Mongkut"s Institute of Technology, Thailand. He completed his $\mathrm{PhD}$ in electrical engineering at Florida Atlantic University, Boca Raton, FL in 2001. Since 2011, he has been working in National Broadcasting and Telecommunications Commission as the secretary to the vice chairman. His PhD work is on the system aspects of Bluetooth, WLAN and Mobile IP/CDPD. His current research interests are in telecommunication planning and related system analysis and efficient spectrum management. He is a member of Tau Beta Pi, Florida Epsilon and was an honorary advisory's chairman of science $\&$ technology committee of parliament in 2009.

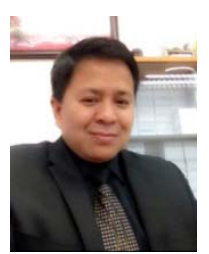

Peerawat Promkladpanao was born in Nong Khai, in 1970, in Thailand. He received his BSc in electrical engineering from the Chulachomklao Royal Military Academy, Nakhon-nayok, Thailand in 1990. He served in the Royal Thai Armed Forces for more than 15 years old. Presently he working as assistant of Vice Chairman of National Broadcasting and Telecommunication Commission (NBTC). His research interests includes LTE design, wireless system.



Yodsapon Thamachareon was born in Bangkok, Thailand on $13 \mathrm{Feb}, 1976$. He received his bachelor of accountant from Dhonburi Rajabhat University 1998. He has been working as an assistant to vice chairman in national broadcasting and telecommunications, Bangkok, Thailand since November 2012. His research interests are in technology management and spectrum management. 